\title{
New Weighted Clustering Approach to Map and Prioritize Learning Knowledge Objects Towards Learning Approaches
}

\author{
http://dx.doi.org/10.3991/ijet.v11i06.5318 \\ Sai Sabitha, Deepti Mehrotra and Abhay Bansal \\ Amity University Uttar Pradesh, India
}

\begin{abstract}
To have a unique learning experience and a high learning impact, diverse courses should be incorporated in e-Learning. Learning Management System, a tool in eLearning manages and delivers content to users. Learning Objects (LO), the course content is the fundamental unit of Learning Management System. Knowledge Object of Knowledge Management System can also be a viable resource in technology supported learning. A learning scenario for a given learner has to be identified. The course content (LO) has to match their learning skills. Data mining techniques can be widely used to find similar objects and $K$ Mean clustering technique can be used to produce more consistent clusters. The clusters can have strong and similar concepts of Learning Knowledge Objects. A new algorithm, a weighted cosine distance that gives real-valued distances between instances which further modifies the structure of the feature space is used for prioritising objects in clusters. These objects can be further mapped to learning approaches of the users. An experiment is conducted by using Learning and Knowledge Objects to understand the effectiveness of the weighted measure, thereby a personalized holistic learning environment is provided to the learners.
\end{abstract}

Index Terms - Deep Learning, K-Mean, Knowledge Objects, Learning Approaches, Learning Object, Metadata.

\section{INTRODUCTION}

e-Learning helps to stabilize and improve the performance of learning by capturing and presenting the subject content in synchronous or asynchronous form. The landscape of learning technology consists of repositories, digital content, adaptive tutors, personalization, course management and collaboration. The standard learning content focuses on content packaging, metadata, accessibility, resource list, sequencing, and sharable resources. The learning system standard involves tool, learner profile, competencies, accessibility, digital repositories, learning design, learning object discovery and delivery.

Learning Management System (LMS) is a widely used tool in e-Learning environment and it needs to focus on content delivery in a new context. The environment has to improve learning by providing additional resources to LOs. These resources can be captured from the Knowledge Base (KB) of the Knowledge Management system (KMS). Knowledge Objects of KMS can be a viable resource in e-Learning[25]. Various theories and models are proposed in the delivery of LOs [6], converging LOs and KOs [32] [34] [35] [36] [38] [40] [47]. These converged objects are called Learning Knowledge Objects (LKO). Many techniques are used for delivery of these
LKOs [5] [29] [36] [37] [46]), This research work uses clusters of LKOs and maps them to learning approaches.

Clustering hypothesis states that, closely associated objects tend to be relevant to the same query request. Similar objects are placed within a cluster, leading to a faster retrieval of objects and effective presentation of information. K-Mean technique is a partition based clustering method. It is a vector quantization approach, and it is uses pair wise Euclidean distances between points. A Euclidean distance is closely tied with cosine or scalar product. It gives an accurate measure of similarity than magnitude. Magnitude is an important element when considering similarity. To find similar LOs \& KOs, cosine measure that gives similarity value between two objects and Euclidean measure that gives the magnitude of objects can be used. These measures provide a different aspect of similarity between two entities.

The research formulates the weights for the LOs \& KOs as a selection criteria for identifying suitable LKOs for different learning approaches. The work proposed involves in creating the most appropriate structure to deliver the objects through clusters and arranging the clusters in a manner that aids

find-ability of the objects. It also provides a new framework for narrowing down an appropriate set of "objects" for different learners thereby providing a faster retrieval and an improved learning experience.

This paper is organized as follows: - Literature Review, Methodology, Experimental Set up, Results and Analysis.

\section{LITERATURE REVIEW}

The theoretical review is based on Learning Content, Design, Development and Delivery as shown in "Fig.1".

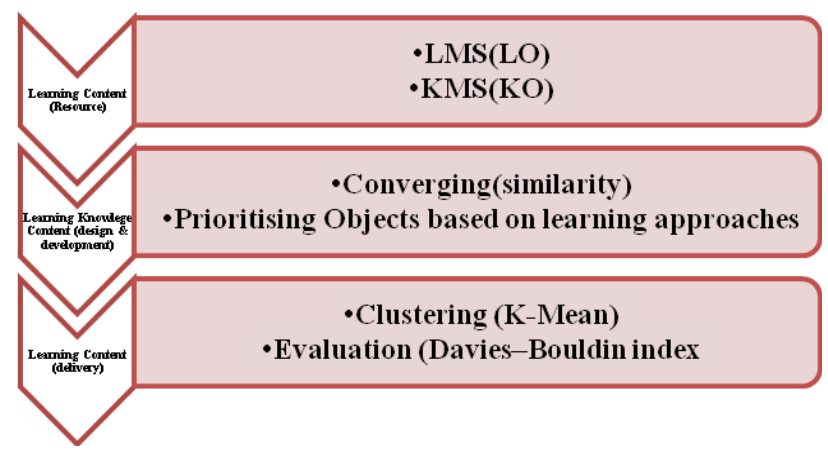

Figure 1. Theoretical Review 


\section{A. Learning Content (Resource)}

The LMS is an application for administration, managing and delivering of learning content within an organization[15]. The Learning objects are independent small pieces of information and should be reused [3][44] [22] [27] [43].

A Learning Object refers to any digital educational resource. Instead of providing all material for an entire course, a particular topic or a lesson can be delivered during technology-supported learning. Broadly speaking, Learning Resources usually refer to documents or collections, whereas Learning Objects are components of a document or collection. LO is comprised of assets like image, text, video, web page.

KMS is based on the Knowledge Management principles supporting knowledge processes and practices of KM like creation, acquisition and sharing [7] [31]. It is a critical factor in the success of any organization. KM objects can also be used in Online Educational System 30] [33] especially in higher education system [18] [19] [25].

The tacit knowledge in a knowledge conversion process can be considered as the content of KOs. According to Merrill [25] a Knowledge Object is a record of information that serves as a building block for KMS. Horton [18] [19] says, "A KO is a chunk of electronic content that may be accessed individually, and that can carry out a single goal"' and it should also be reusable.

\section{B. Learning Content (Design \& Development)}

Learning is an ever evolving process, improving the overall effectiveness of the teaching learning process, Bloom has given a clear outline of the learning objectives [2], learning styles [12] [24] and learning approaches [11] [12] [23] of a learner. These approaches can be broadly categorized as follows:

- Surface/basic learners are aiming to reproduce the study material in a test or exam rather than actually understanding it.

- Strategic learners intend to obtain high grades and organise their time and distribute their effort to greatest effect.

- In deeper approach, learners are aiming towards understanding it. Higher education learners can belong to this category.

Regardless of students' preferences, the goal of learning is to make the users understand the concept and successfully apply them.

\section{Feature weights}

Data pre-processing is an important step in data mining, which improves the quality of data. It includes cleaning, normalization, transformation and selection. Feature weighting, a data pre processing technique is used to approximate the influence of individual feature in a set. The relevant attribute has a higher weight value, whereas irrelevant features are given a weight closer to zero. The need for attribute weight setting and its advantages are discussed in the research work [10][28]. In mining a dataset, all features may or may not be relevant or correct, and clustering can benefit from using a selected subset of the features. Many research works on feature weighting are proposed [4] [8] [13] [14] [20] [21] [26] [39] [42] [45].

\section{Similarity Measure}

Many clustering methods use distance measure to determine the similarity or dissimilarity between any pair of objects. Different distance measures are available for binary, ordinal, categorical and continuous data types. Similarity (proximity) compares the two vectors $a$ and $b$ and Cosine, Jaccard, Dice are some of the methods of proximity measures. Cosine similarity, uses similarity scores of an object in a given data set. This measure takes two argument vec $A$ and vec $B$ as parameter which are a vector representation of the object's content $\mathrm{A}$ and $\mathrm{B}$, and returns the similarity score, which lies between 1 and 0 , indicating that the two are completely similar (1) or dissimilar (0). Refer "(1)".

$$
\text { Similarity }=\cos (\theta)=(A . B)\left|\|A\| B \|=\sum_{i}^{n}\left(A_{i} \cdot B_{i}\right)\right|\left(\sqrt{\sum_{i}^{n}}\left(A_{i}\right)^{2}\right) \cdot\left(\sqrt{\sum_{i}^{n}}\left(B_{i}\right)^{2}\right)
$$

\section{E. Learning Content (Delivery)}

A good clustering method produces high quality clusters with high similarity and inter class dissimilarity [17]. Clusters are formed based on "distance" between points. Two major classes of distance measures are Euclidean and non-Euclidean distance measures (Jacquard, Cosine). The clustering methods can be broadly classified as the Partition, Hierarchy, Density-Based, Grid-Based and ModelBased techniques. K-Mean is a simple, partition based approach [17] [41].

K-Mean clustering Algorithm as follows:

1. Determine the value of ' $K$ '.

2. Select ' $K$ ' random objects from the data set as initial points (center) of the cluster.

3. Each object is compared with the initial points (center) and the distance is calculated.

4. The points to the closest center point is assigned.

5. The mean is calculated for each cluster and the center point is updated with the new mean point.

6. Repeat step 3 till there is no assignment of objects to clusters. The distance is calculated using "(2)":

$$
\sum_{m=1}^{k} \sum_{t_{m i} \in K m}\left(C_{m}-t_{m i}\right)^{2}
$$

\section{F. Evaluating Measures -Silhouette index}

$\mathrm{K}^{\prime}$ in K-Mean algorithm is an important criterion in determining the number of clusters. Elbow method, cross validation and silhouette index are some of the methods used in determining the value of ' $\mathrm{K}$ '. Silhouette coefficient uses the average distance to elements in the same cluster with the average distance to elements in other clusters [9].

- Cohesion a (x): average distance of $\mathrm{x}$ to all other vectors in the same cluster.

- Separation $\mathrm{b}(\mathrm{x})$ : average distance of $\mathrm{x}$ to the vectors in other clusters.

Silhouette coefficient is shown in: - (3)

$$
s(x)=\{b(x)-a(x)\} / \max \{a(x), b(x)\}
$$


The value of s (x) lies between $[-1,+1]$ : Objects with a high silhouette value are considered well clustered and objects with a low value may be outliers. This index works well with K-Mean clustering, and is also used to determine the optimal number of clusters

\section{G. Evaluating Measures $-D B$ Index}

Cluster validity assessment, is the process of evaluating the results of a clustering. Finding an optimal cluster is an important criterion. External, Internal and Relative are the three different criteria used clustering algorithms.

Internal and External criteria use statistical methods and Relative criteria compares different clustering schema with validity indices. The various validity indices are Davies Bouldin Index, Root Mean Square Standard Deviation (RMSSDT) Index, Dunn Index [16]. The DaviesBouldin index is calculated by the formula given below: "(4)".

$$
D B=(1 / n) \sum_{i}^{n} \max _{\substack{i \neq j \\
i \neq j}}\left\{\left(\begin{array}{c}
\sigma \\
i
\end{array}+\underset{j}{\sigma}\right) / d\left(\begin{array}{c}
c, c \\
i
\end{array}\right)\right\}
$$

Algorithms that produce clusters with low intra-cluster distances (high intra-cluster similarity) and high intercluster distances (low inter-cluster similarity) will have a low Davies-Bouldin index. This measure is considered as an evaluation measure for clusters in K-Mean technique. The methodology used is discussed in the next section.

\section{Methodology}

The proposed methodology is shown in a flowchart Refer "Fig.2".

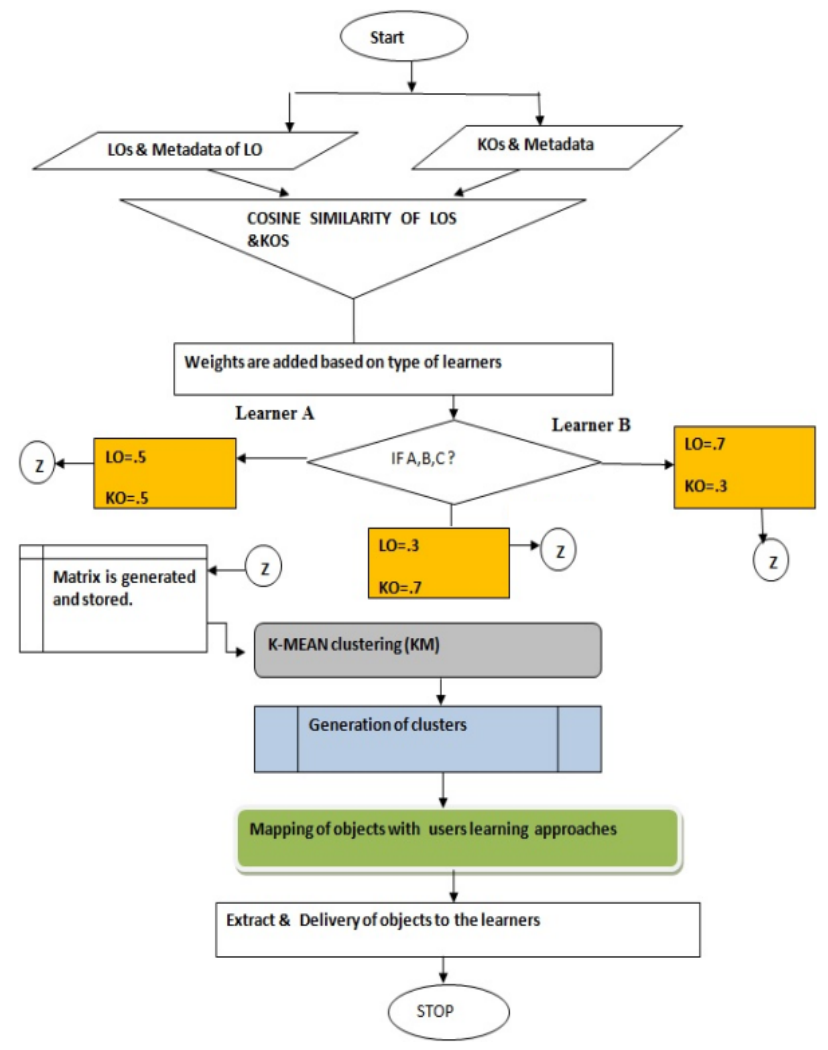

Figure 2. Flow chart depicting the process flow of the experiment.

\section{A. Steps of Flowchart}

1. LOs \& KOs and their Metadata are considered.

2. Evaluation of the Metadata and feature selection is done.

3. Generation of cosine matrix for LOs and KOs

4. The values are stored in "cosine.dat" file.

5. Assigning weights to the cosine matrix for three groups of learners

- Learner A - Basic Learner

- Learner B - Strategic Learner

- Learner C - Advance Learner

6. Identification of the appropriate value of ' $\mathrm{K}$ ' in $\mathrm{K}$ Mean.

7. Generation of clusters using K-Mean.

8. Based on a topic, intended for study and students learning approaches, suitable LKO's can be filtered and delivered.

\section{B. Need of weighted clustering \& choice of weights}

In weighted clustering, every element is associated with a real valued weight, representing its mass or importance. The algorithms that always respond to weights are as KMean and K-Median. Algorithms such as single-linkage, complete-linkage, ignore weights. Clustering changes depending on the underlying weights [1].Few advantages of adding weights are as follows:

- Accessibility of different objects may have varying importance.

- The weighted approach can prioritize certain objects.

- Since the objects can be distributed, the weighted approach can enable quick access and delivery.

- The various weights considered for the experiments are shown in "Fig.3".

\begin{tabular}{|l|lll|}
\hline Experimentl & LO & KO & Remark \\
\hline Experights & $\begin{array}{l}\text { Weights } \\
\text { added } \\
\text { LO }\end{array}$ & KO & $\begin{array}{l}\text { No w eights are added for Strategic } \\
\text { learners }\end{array}$ \\
\hline Weights & .7 & .3 & $\begin{array}{l}\text { Higher weights are given to LOs } \\
\text { compared to KOs thereby more LOs } \\
\text { are targeted for basic learners }\end{array}$ \\
\hline Experiment3 & LO & KO 1 & $\begin{array}{l}\text { Higher weights are given to KOs } \\
\text { compared to LOs thereby mor KOs } \\
\text { are targeted for deep learners }\end{array}$ \\
\hline
\end{tabular}

Figure 3. Choice of weights

I. Surface/basic learners (Group 'A'), adopt a surface approach by memorizing facts and to them suitable LOs for a given topic can be delivered. In this case of delivery of LKOs, the Learning Objects will be given higher weights compared to $\mathrm{KO}$.

II. Strategic learners (Group 'B'), are well organized and are efficient in their learning, to them LKOs can be delivered. In this case equal weights are considered for the LOs as well as KOs or no weights.

III. Deep Learners (Group 'C'), try to understand the learning content. Many advanced learner's fall into this category and for them KOs can be given. In this delivery of LKOs, Knowledge Objects will be given higher weights compared to LOs. 


\section{DATA SET \& EXPERIMENTAL SETUP}

\section{A. Data Set \& Generation of cosine matrix}

A set of 75 LOs \& $49 \mathrm{KOs}$ is considered from the Learning Knowledge System, which are the classified objects based on user queries for the topic "data mining". The Metadata considered are Id, Title, Topic, Sub Topic, Content and Category for both LO and KOs.

\section{B. Feature selection of weights}

Rapid Miner, tool is used to check the relevance/weight of the attributes. The tool converts Attribute Weights into a ranking structure. The Largest weight is 1 and smallest weight is ' $p$ ', the number of attributes considered. Attributes Title, Topic, SubTopic, Content, Category is considered for weight selection. The output of the tool is shown in "Fig.4."

"Fig.4", represents the attribute "content" has a higher weight. Cosine similarity is applied to the attribute content of the LKO and the weights are added to it.

\section{Experimental Approach}

As discussed in the previous section, to calculate the proximity (similarity) between two objects, cosine similarity measure which returns values of interval $[-1,1]$. The similarity of the contents is converted into $124 \times 124$ matrix as given below "Fig.5".

Weights are added to this cosine similarity matrix. A python program is used to generate the new weighted matrix. The input variables and steps followed are described in "Fig.6".

\section{Choice of ' $K$ ': Silhouette coefficient}

Objects with a high silhouette value are considered well clustered and can be used to determine the optimal number of clusters in ' $\mathrm{K}$ '-Mean. This measure is suitable for estimating the best partition of the cluster (Refer eq 3). The average silhouette for $\mathrm{K}=3,4,5,6$ are $0.028,0.034,0.017$ and 0.031 respectively. The value of ' $\mathrm{K}$ '=4 has the highest silhouette value and it is considered as an appropriate value for ' $\mathrm{K}$ ' in $\mathrm{K}$-Mean algorithm. The rapid miner tool was used for creating clusters. The clusters obtained for the three matrices were discussed in "Fig.6".

\section{OUTPUT \& ANALYSIS}

\section{A. Clusters \& LKOs}

"Fig.7", represents the output of various clusters for the three matrices:

- No weights

- Greater weights for LOs

- Greater Weights for KOs.

The graph shows the following findings:

- Number of LOs has increased in cluster0 when greater weights are given to LO.

- Number of KOs, has increased in cluster2 when greater weights are given to $\mathrm{KO}$

\section{B. Learning Index \& Knowledge Index (Output \&Graph)}

Learning Index and a Knowledge Index is calculated using the metric given below: - (Refer "(5)" and "(6)".
The average LI \& KI of four clusters (cluster0, cluster1, cluster2, cluster3) for the three experiments and the corresponding bar chart is shown in "Fig.8a" and "Fig.8b".

1. Learning index (LI) is given as:

$$
\mathrm{LI}=\frac{\text { Total no of LOs in a cluster }}{\text { Total no of objects in a cluster }}(5)
$$

2. Knowledge index $(\mathrm{KI})$ is given as:

$$
\mathrm{KI}=\frac{\text { Total no of KOs in a cluster }}{\text { Total no of objects in a cluster }}(6)
$$

The output shows that the Learning Index of two clusters have increased when the weights are set as $\mathrm{LO}=.7$ and $\mathrm{KO}=.3$ ("Fig. 8 "). The Learning index of cluster0 is 41.8889 and cluster 3 is 13.76 .

Knowledge Index of 3 clusters has increased for the weights set as $\mathrm{LO}=.3$ and $\mathrm{KO}=.7$ ("Fig.9"). The objects are packed within few clusters and thereby weighted approach prioritizes certain objects and enables in quick access and delivery.

\begin{tabular}{l|l|l|}
\hline File Edit Process Iools View Help \\
\hline \multicolumn{3}{|c|}{ Table View $\bigcirc$ Plot View $\bigcirc$ Annotations } \\
\hline \multicolumn{3}{|c|}{ attribute } \\
\hline CATEGORY & 5 \\
\hline AUTHOR & 4 \\
\hline TOPIC & 3 \\
\hline SUBTOPIC & 2 \\
\hline CONTENT & & 1 \\
\hline
\end{tabular}

Figure 4. Feature Selection (Attribute Weights)

\begin{tabular}{|r|r|r|r|r|r|r|}
\hline objects & 1 & 2 & 3 & 4 & 5 & 6 \\
\cline { 2 - 7 } & 1 & 0.2877408 & 0.04241506 & 0.12719396 & 0.0149191 & 0.06201117 \\
\hline 2 & 0.2877408 & 1 & 0.04661949 & 0.02967865 & 0.0447875 & 0.0229462 \\
\hline 3 & 0.04241506 & 0.04661949 & 1 & 0.02202368 & 0.033167 & 0.0391691 \\
\hline 4 & 0.12719396 & 0.02967865 & 0.02202368 & 1 & 0.021821 & 0.04155542 \\
\hline 5 & 0.01491909 & 0.0447875 & 0.03316704 & 0.02182096 & 1 & 0.01034268 \\
\hline 6 & 0.06201117 & 0.0229462 & 0.0391691 & 0.04155542 & 0.0103427 & 1 \\
\hline 7 & 0 & 0.00929637 & 0.00586089 & 0.00866214 & 0.1297248 & 0.00614684 \\
\hline 8 & 0.03396251 & 0.05454494 & 0.01825525 & 0.01766519 & 0.0197808 & 0.04134843 \\
\hline 9 & 0.12719396 & 0.02967865 & 0.02202368 & 1 & 0.021821 & 0.04155542 \\
\hline 10 & 0.03076241 & 0.07815726 & 0.04826957 & 0.03930328 & 0.0385777 & 0.03295555 \\
\hline 11 & 0.08882356 & 0.01641302 & 0.01495233 & 0.05619985 & 0.0176979 & 0.01337939 \\
\hline
\end{tabular}

Figure 5. Proximity measures of LO\& KO in matrix.

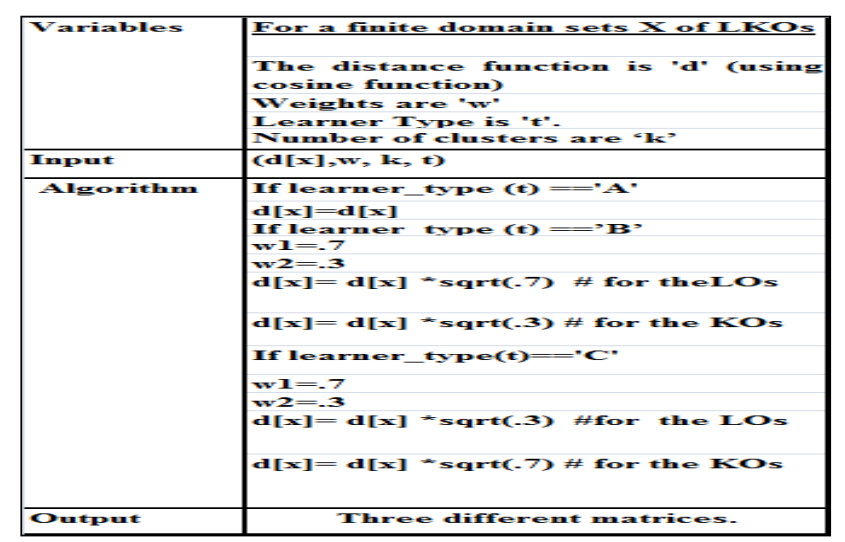

Figure 6. Algorithm used for generation of weighted matrix 

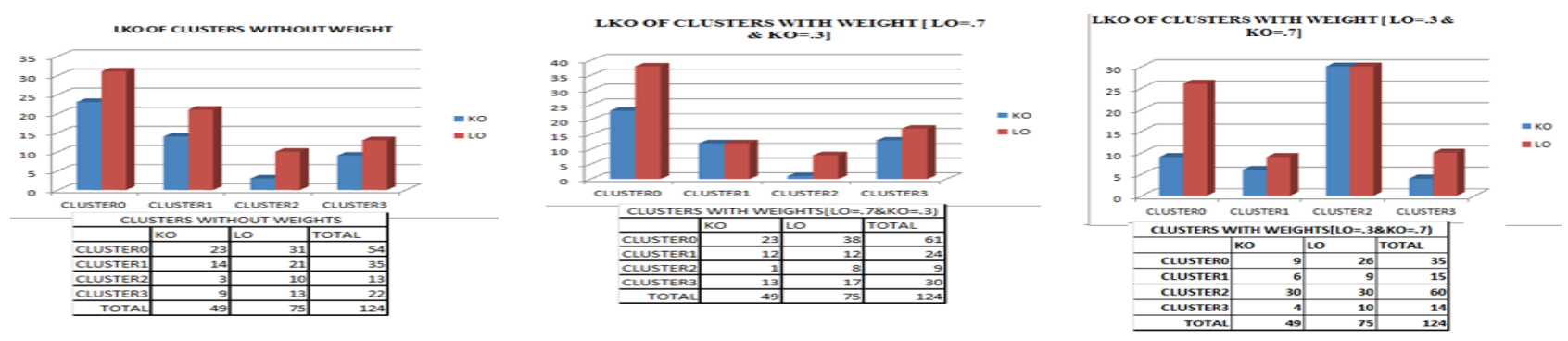

Figure 7. LKOs in different clusters
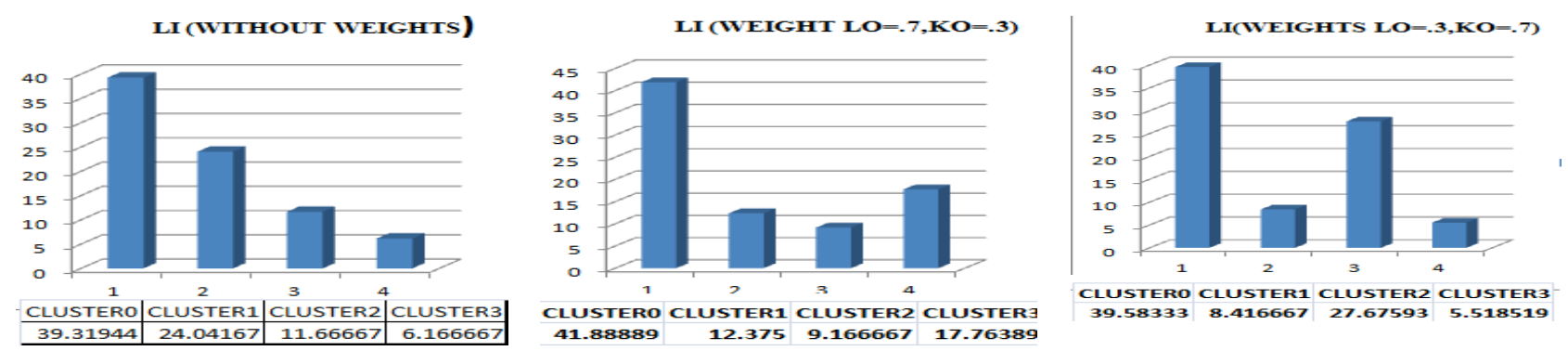

Figure 8. Bar charts of Learning Index for different weights
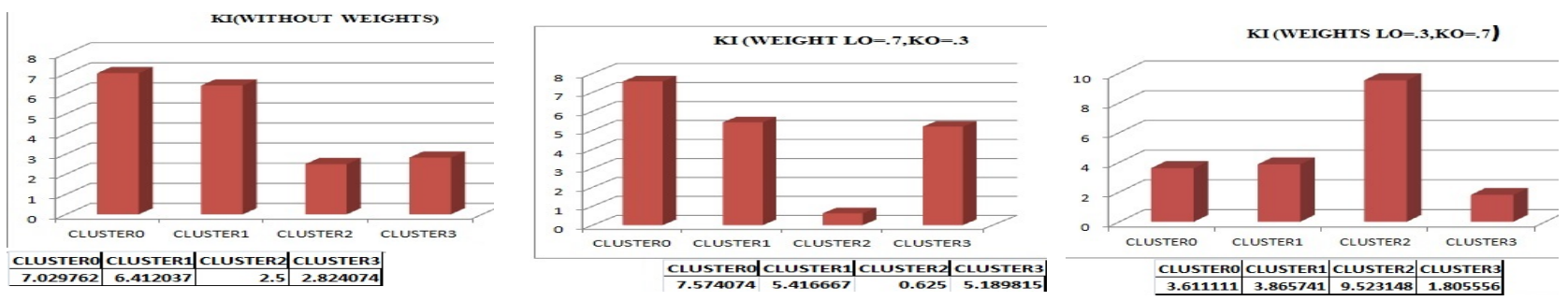

Figure 9. Bar charts of Knowledge Index for different weights

\section{Evaluation of the clusters}

The three cluster models and the clusters along with the DB index are shown in "Fig.10". The clustering algorithm that produces a collection of clusters with the smallest Davies-Bouldin index is considered the best algorithm based on this criterion. According to this index the clusters with weights has the smallest values $(0.30 \& 0.32)$ as compared to clusters without weights (0.35) "Fig.10".

\begin{tabular}{|c|c|c|}
\hline $\begin{array}{l}\text { LKOs of cluster } \\
\text { without weights }\end{array}$ & $\begin{array}{l}\text { LKOs of cluster with } \\
\text { weights }[\mathrm{LO}=.7 \& \mathrm{KO}=.3]\end{array}$ & $\begin{array}{l}\text { LKOs of cluster with } \\
\text { weights }[\mathrm{LO}=. \\
\& \mathrm{KO}=.7]\end{array}$ \\
\hline (-) Text View $\bigcirc$ Annotations & 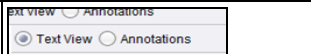 & Pear Wew $O$ Annotatons \\
\hline $\begin{array}{l}\text { Davies Bouldin } \\
\text { Davies Bouldin: } 0.035\end{array}$ & $\begin{array}{l}\text { Davies Bouldin } \\
\text { Davies Bouldin: } 0.030\end{array}$ & Davies Bouldin \\
\hline
\end{tabular}

Figure 10. Performance Measure (DB index)

\section{CASE STUdy}

Access and delivery of LKOs for the learners can be as follows. (Refer Table1):

I. For Surface/Basic learner most of the LOs can be fetched from Cluster0 Cluster1 whose scale is greater than six.(Refer Table1)

II. For Strategic learner most of the suitable LKOs can be fetched from Cluster0, Cluster1 and Cluster3 whose scale is 6-10.

III. For Deep learner most of the KOs can be fetched from Cluster2 whose scale is 10 "Fig.11".

The normalised (Min-Max Normalisation) values for Learning Index and Knowledge Index for each metric in the scale of 1-10 is shown in Table 1.
Surface Learners

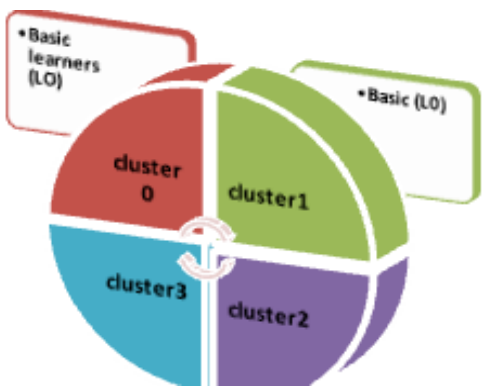

Deep Learners

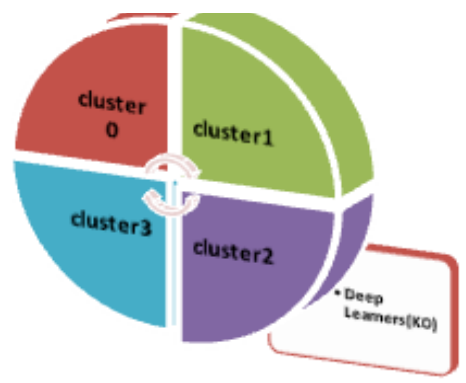

Figure 11. Mapping of clusters with learners

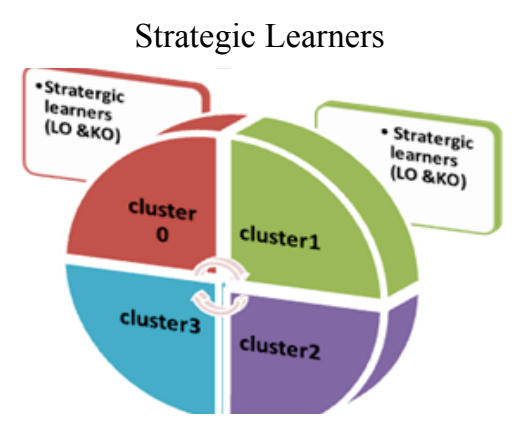


TABLE I.

NORMALISED INDEX (LI\&KI)

\begin{tabular}{|c|c|c|c|}
\hline & \multicolumn{3}{|c|}{ Normalized LI in scale 1-10 } \\
\hline Clusters & No weights & $\begin{array}{c}\text { With } L O=.7 \& \\
K O=.3\end{array}$ & $\begin{array}{c}\text { With } \mathrm{KO}=.7 \& \\
\mathrm{LO}=.3\end{array}$ \\
\hline CLUSTER0 & 10.00 & 10 & 10 \\
\hline CLUSTER1 & 5.85 & 1.884321516 & 1.764135987 \\
\hline CLUSTER2 & 2.49 & 1.001650367 & 6.853091422 \\
\hline \multirow[t]{2}{*}{ CLUSTER3 } & 1.00 & 3.365525672 & 1 \\
\hline & \multicolumn{3}{|c|}{ Normalized KI in scale 1-10 } \\
\hline Clusters & No weights & $\begin{array}{c}\text { With } L O=.7 \& \\
K O=.3\end{array}$ & $\begin{array}{c}\text { With } \mathrm{KO}=.7 \& \\
\mathrm{LO}=.3\end{array}$ \\
\hline CLUSTER0 & 10 & 10 & 3.10 \\
\hline CLUSTER1 & 8.79 & 7.24 & 3.33 \\
\hline CLUSTER2 & 1 & 1 & 10 \\
\hline CLUSTER3 & 1.64 & 6.96 & 1 \\
\hline
\end{tabular}

\section{CONCLUSION}

The subject matter from an expert along with a well defined content on a particular topic can give a new dimension to the learning design and can bring credibility to the concepts. The material that a learner receives in a topic for a subject during learning could be blended with appropriate KOs and thereby a knowledge enriched learning environment can be provided to the users. In this research work, clustering based on weighted cosine distance was adopted. This method uses weights to attribute "content" during the clustering process and it makes full use of the characteristics of the data distribution as well as increasing the accuracy of the clustering results. The experimental result shows the technique used is capable of producing a partition that is as good as or better than the best individual clustering. The new algorithm improves the findability of objects within the clusters and the quality of clusters is confirmed using the DB index. The implications and findings of the research will help better and appropriate delivery of objects based on different learners. The variation of weights may give different clusters. Analysis can also be carried out with other clustering algorithms that respond to weights. The weights can be also defined and added based on learners' feedback. The work can be further studied using cluster ensemble techniques.

\section{REFERENCES}

[1] Ackerman, M., Ben-David, S., Branzei, S., \& Loker, D. (2012). Weighted Clustering. In AAAI (pp. 858-863).

[2] Anderson, T. (2004). Theory and practice of online learning. Athabasca University: AU Press.

[3] Barron, T., (2000, November). Learning Object Pioneers. ASTD Learning Circuits. Retrieved 31 July, 2005, http://www.learningcircuits.org/2000/mar2000/barron.htm.

[4] Chan, Y., Ching, W. K., Ng M. K., and Huang J. Z. (2004), An optimization algorithm for clustering using weighted dissimilarity measures. Pattern Recognition. 37:5, pp. 943-952. http://dx.doi.org/10.1016/j.patcog.2003.11.003

[5] Chiu, K. H., Lee, T. K., \& Wang, T. I. (2006). A learning objects recommendation model based on the preference and ontological approaches. In Advanced Learning Technologies, 2006. Sixth International Conference on (pp. 36-40). IEEE

[6] da Silva, P. F., \& Mustaro, P. N. (2009, October). Clustering of learning objects with Self-Organizing Maps. In Frontiers in Education Conference, 2009. FIE'09. 39th IEEE (pp. 1-6). IEEE. http://dx.doi.org/10.1109/fie.2009.5350542
[7] Davenport, T. H., \& Prusak, L. (1998). Working knowledge: How organizations manage what they know. Harvard Business Press.

[8] De sarbo, W. S., Carroll, J. D., Clark, L. A., Green, P. E. (1984) Synthesized clustering: A method for amalgamating clustering bases with differential weighting variables. Psychometrika. 49:1, pp. 57-78.

[9] Desgraupes, B. (2013). Clustering Indices. University Paris Ouest Lab Modal'X.

[10] Domeniconi, Carlotta\& Muna Al-Razgan (2009). "Weighted cluster ensembles: Methods and analysis." ACM Transactions on Knowledge Discovery from Data (TKDD) 2.4 (2009): 17.

[11] Entwistle N. J., (1988) "Motivational Factors in Students' Approaches to Learning," in Schmeck, R.R., ed., Learning Strategies and Learning Styles, Plenum Press, New York. http://dx.doi.org/10.1007/978-1-4899-2118-5_2

[12] Felder, R. M., \& Brent, R. (2005). Understanding student differences. Journal of engineering education, 94(1), 5772http://dx.doi.org/10.1002/j.2168-9830.2005.tb00829.x

[13] Frigui, H., Nasraoui, O. (2004) Unsupervised learning of prototypes and attribute weights, Pattern Recognition. 37, pp. 567-581. http://dx.doi.org/10.1016/j.patcog.2003.08.002

[14] Green, P. E., Carmone, J., Kim, J. (1990) A preliminary study of optimal variable weighting in K-Meanclustering. Journal of Classification, 7:2, pp. 271-285. http://dx.doi.org/10.1007/BF0190 $\underline{8720}$

[15] Greenberg, L. (2002). LMS and LCMS: What's the Difference. Learning Circuits, http://scripts.cac.psu.edu/

[16] Halkidi, M., Batistakis, Y., \& Vazirgiannis, M. (2001). On clustering validation techniques. Journal of Intelligent Information Systems, 17(2-3), 107-145. http://dx.doi.org/10.1023/A:101280161 2483

[17] Han \& Kamber. (2008)"Data Mining Concepts \& Techniques" Elsevier.version 3 Publisher: Morgan Kaufmann Publishers.

[18] Horton, W. (2001). Developing Knowledge Products, Bolder, CO.William Horton Consulting.

[19] Horton, W. (2006). E-learning by design. San francisco.Pfeiffer

[20] Huang J. Z., Ng M. K., Rong, H., and Li, Z. (2005), Automated variable weighting in K-Meantype clustering. IEEE Transactions on Pattern Analysis and Machine Learning, 27:5, pp. 657-668. http://dx.doi.org/10.1109/TPAMI.2005.95

[21] Huang, J. Z., Xu, J., Ng, M. And Ye, Y. (2008) Weighting Method for Feature Selection in K-Means. In: H. Liu and H. Motoda (Ed.) Computational Methods of Feature Selection, Chapman \& Hall/CRC, pp 193-209.

[22] IEEE LTSC (2002). Learning Technology Standards Committee (LTSC) IEEE Standard for Learning Object Metadata. 1484.12.12002. http://tsc.ieee.org/wg12/.

[23] Jackie L. (2003).Deep, surface and strategic approaches to learning Good Practice in Teaching and Learning, Centre for Teaching and Learning. Retrieved from: http://www2.warwick.ac.uk/services/ldc/development/pga/introtan dl/resources/2a_deep_surfacestrategic_approaches_to_learning.pd $\mathrm{f}$

[24] Keefe, J. W. (1979). Learning style: An overview. In NASSP's Student learning styles: Diagnosing and prescribing programs (pp. 1-17). Reston, VA: National Association of Secondary School Principals.

[25] Merrill, M. D. (2000). Knowledge objects and mental models. In Advanced Learning Technologies, 2000. IWALT 2000. Proceedings. International Workshop on (pp. 244-246). IEEE. http://dx.doi.org/10.1109/iwalt.2000.890621

[26] Modha, D.S., Spangler, W.S. (2003) Feature weighting in KMeanclustering, Machine Learning. 52, pp. 217-237 http://dx.doi.org/10.1023/A:1024016609528

[27] Mortimer (2002).Learning objects of desire: Promise and practicality. Learning Circuits Retrieved May12, 2006 http://www.Learningcircuits.org/2002/apr2002/mortimer.html.

[28] Nock, R., \& Nielsen, F. (2006)"On weighting clustering", IEEE Transactions on Pattern Analysis \& Machine Intelligence, vol.28, no. 8, pp. 1223-1235, August 2006, http://dx.doi.org/10.1109/ TPAMI.2006.168 
[29] Ochoa, X., \& Duval, E. (2008). Relevance Ranking Metrics for learning objects. Learning Technologies, IEEE Transactions on, 1(1), 34-48. http://dx.doi.org/10.1109/TLT.2008.1

[30] Rahimi, H., Arbabisarjou, A., Allameh, S. M., \& Aghababaei, R. (2011). Relationship between knowledge management process and creativity among faculty members in the university. Interdisciplinary Journal of Information, Knowledge, and Management, 6, 1733

[31] Rowley, J. (2000). Is higher education ready for knowledge management?. International Journal of Educational Management, 14(7), 325-333. http://dx.doi.org/10.1108/09513540010378978

[32] Ruffner, J., \& Deibler, N.,(2008). Knowledge Objects and Learning Objects: Birds of a Feather or Different Species Altogether Proceedings of the Inter service /Industry Training, Simulation \& Education Conference (I/ITSEC), Orlando, FL

[33] Saade, R., Nebebe, F., \& Mak, T. (2011). Knowledge management systems development: Theory and practice. Interdisciplinary Journal of Information, Knowledge, and Management, 6, 35-72.

[34] Sabitha, A.S, Mehrotra, D., Bansal (2014a). Enhanced Learning by Extending Metadata of Learning Objects with Knowledge Objects. International Journal of Education and Learning Vol.3, No.1 (2014), pp.1-12 . http://dx.doi.org/10.14257/ijel.2014.3.1.01. http://dx.doi.org/10.14257/ijel.2014.3.1.01

[35] Sabitha, S., Mehrotra, D., \& Bansal, B. (2014b). A data mining approach to improve re-accessibility and delivery of learning knowledge objects. Interdisciplinary Journal of E-Learning and Learning Objects, 10, 247-268. Retreived from: http://www.ijello.org/Volume10/IJELLOv10p247267Sabitha0874.pdf

[36] Sabitha S, Mehrotra D, and Bansal A (2015 a). Knowledge Enriched Learning by Converging Knowledge Object \& Learning Object. The Electronic Journal of e-Learning Volume 13 Issue 1 2015, (pp3-13).

[37] Sabitha, S., Mehrotra, D., \& Bansal, B. (2015b.). Delivery of learning knowledge objects using fuzzy clustering. Education and information technologies. DOI 10.1007/s10639-015-9385-5. Springer Science+Business Media New York 2015

[38] Sampson, D. G., \& Zervas, P. (2013). Learning object repositories as knowledge management systems. Knowledge Management \& E-Learning: An International Journal (KM\&EL), 5(2), 117-136.

[39] Strehl, A., Ghosh, J., Mooney, R. J., Impact of similarity measures on web-page clustering. Proc. of AAAI Workshop on AI for Web Search, 2000

[40] Štuikys, V., \& Damaševičius, R. (2007). Towards knowledgebased generative learning objects. Information technology and control, 36(2), 202-212.

[41] Tan, P.N., Steinbach, M., \& Kumar,V. (2007). Introduction to Data Mining: Pearson Education (6th ed.), India. Chapter 9, page 624, ISBN: 978-81-317-1472-0

[42] Tsai, C.Y., Chiu, C.C. (2008) Developing a feature weight adjustment mechanism for a K-Meanclustering algorithm, Computational Statistics and Data Analysis. 52, pp. 4658-4672. http://dx.doi.org/10.1016/j.csda.2008.03.002

[43] Wagner, E., (2002). Steps to creating a Content Strategy for your organization. e-Learning Developers' Journal. ELearning Guild. Retrieved http://www.elearningguild.com/pdf/2/102902MGT-H.pdf

[44] Wiley, D.A. (2000). Connecting learning objects to instructional design theory: A definition, a metaphor, and a taxonomy. The Instructional Use of Learning Objects: Available at http:// reusability.org/read/chapters/wiley.doc.
[45] Xing, E. P., Ng, A. Y., Jordan, M. I., and Russell, S. (2003). Distance metric learning, with application to clustering with side information. Advances in Neural Information Processing Systems, vol 15, pp. 505-512.

[46] Yen, N. Y., Shih, T. K., Chao, L. R., \& Jin, Q. (2010). Ranking metrics and search guidance for learning object repository. Learning Technologies, IEEE Transactions on, 3(3), 250-264. http://dx.doi.org/10.1109/TLT.2010.15

[47] Zouaq, A., Nkambou, R., \& Frasson, C. (2007). Using a competence model to aggregate learning knowledge objects. In Advanced Learning Technologies, 2007. ICALT 2007. http://dx.doi.org/10.1109/ICALT.2007.273

\section{AUTHORS}

Mrs Sai Sabitha is BE (CS), ME (CS) in Computer Science and engineering. She is Associate Professor (CSE), Amity University. She is pursuing Ph.D. Programming in Computer Science \& Engineering in ASET, Amity University. She has published many research papers in conferences \& journals. She has over 14 years of Academic and industry experiences. She has handled various B. Tech \& M. Tech Projects. Her area of interests are e-Learning, Knowledge Management, Data Mining, Artificial Intelligence \& Web Technologies.

Dr. Deepti Mehrotra received her Ph.D. from Lucknow University and currently she is working as Professor in Amity school of Engineering and Technology, Amity University, Noida. Earlier she worked as Director of Amity School of Computer Science, Noida, India. She has more than 20 years of research, teaching and content writing experience. She has published more than 80 papers in international refereed Journals and conference Proceedings. She is editor and reviewer for many books, referred journal and conferences. She is regularly invited as resource person for FDPs and invited talk in national and international conferences. She guided Ph.D. and M.Tech students.

Prof. (Dr.) Abhay Bansal is BE (CS), ME (IT), MBA and $\mathrm{PhD}$. He is Joint Acting Head, ASET, Professor \& HOD (CSE), ASET \& Director, DICET, Amity University, Noida. With over 21 years of Industry and Academic Experience, Dr. Bansal has regularly contributed more than 70 papers in various International journals/conferences. He is a Fellow of the Institution of Engineering and Technology (U.K), Sr. Member, International Association of Computer Science and Information Technology. He is a member of ISTE, SMIEEE (USA), SMACM, IETE. He is also a Microsoft Certified Professional and Microsoft approved Technical Associate. He has been an active member and Chairman of the programme committees of several National and International conference/seminar. He is also a reviewer of various $\mathrm{Na}-$ tional/ International Journals of repute.

Submitted, 09 March 2016. Published as resubmitted by the authors on 09 April 2016. 